\title{
The efficacy of mometasone furoate for children with asthma: a meta-analysis of randomized controlled trials
}

\author{
Yanling Song ${ }^{1}$, Kaiyu Pan², Yuyan Chen ${ }^{1}$, Xiaoming Wang ${ }^{1}$, Jun Tian ${ }^{2}$
}

${ }^{1}$ Department of Paediatrics, The First Affiliated Hospital of Zhejiang Chinese Medical University, Hangzhou, Zhejiang Province, China 2Department of Paediatrics, The First People's Hospital of Xiaoshan, Hangzhou, Zhejiang Province, China

\begin{abstract}
Introduction: The influence of mometasone furoate for paediatric asthma remains controversial. Aim: We conducted a systematic review and meta-analysis to explore the efficacy and safety of mometasone furoate for paediatric asthma.

Material and methods: We have searched PubMed, Embase, Web of science, EBSCO, and Cochrane library databases through October 2019 for randomized controlled trials assessing the effect of mometasone furoate versus placebo for paediatric asthma. This meta-analysis was performed using the random-effects model.

Results: Four RCTs were included in the meta-analysis. Overall, as compared to placebo for paediatric asthma, mometasone furoate is associated with substantially increased predicted forced expiratory volume in $1 \mathrm{~s}\left(\mathrm{FEV}_{1}\right)$ (mean difference $(M D)=7.53 ; 95 \% \mathrm{Cl}: 7.02-8.04 ; p<0.00001)$, FEV $(\mathrm{MD}=0.11 ; 95 \% \mathrm{Cl}: 0.10-0.12 ; p<0.00001)$, and morning peak expiratory flow (AM PEF) (MD = 17.70; 95\% Cl: 9.91-25.49; $p<0.00001)$, but demonstrates no obvious effect on pharyngitis ( $R R=0.96 ; 95 \% \mathrm{Cl}: 0.59-1.58 ; p=0.89)$, upper respiratory tract infections $(\mathrm{RR}=0.73$; 95\% Cl: 0.50-1.05; $p=0.09$ ), or adverse events ( $R R=1.05 ; 95 \% \mathrm{Cl}: 0.84-1.31 ; p=0.69$ ).

Conclusions: Mometasone furoate may be effective and safe for paediatric asthma.
\end{abstract}

Key words: mometasone furoate, paediatric asthma, forced expiratory volume in $1 \mathrm{~s}$, randomized controlled trials.

\section{Introduction}

Asthma has become one of the most common chronic medical conditions and about 300 million people globally are estimated to suffer from asthma [1-3]. Asthma is also regarded as the most common chronic disorder in children $[4,5]$. This disease can result in considerable morbidity and remarkably reduced quality of life in paediatric populations, and hospitalizations and urgent medical care is sometimes required for these patients $[6,7]$. Inhaled corticosteroid (ICS) is currently accepted as the most effective anti-inflammatory medications for the treatment of paediatric asthma and is recommended by international guidelines [8].

Mometasone furoate, a potent ICS has high binding affinity to the glucocorticoid receptor in order to inhibit production of inflammatory mediators and cytokines [912]. Mometasone furoate has the features of low systemic bioavailability by inhalation, and high plasma protein binding because of slow diffusion from the bloodstream into other tissues throughout the body [13]. In adults and children as young as aged 4 years, mometasone furoate is reported to have efficacy in improving the lung function, reducing symptoms, and reducing the frequency and severity of exacerbations [14-17].

Recently, several studies reporting mometasone furoate for paediatric asthma have been published, but their efficacy has not been well established.

\section{Aim}

With accumulating evidence, we therefore have performed a systematic review and meta-analysis of RCTs to compare the efficacy and safety of mometasone furoate versus placebo for paediatric asthma patients.

\section{Material and methods}

Ethical approval and patient consent were not required because this was a systematic review and meta-

Address for correspondence: Jun Tian, Department of Paediatrics, The First People's Hospital of Xiaoshan, Hangzhou, Zhejiang Province, 199 Shixin Road, Hangzhou 311201, Zhejiang, China, phone/fax: +86 057183807019, e-mail: tianjun67173282@163.com Received: 30.11.2019, accepted: 17.12.2019. 
analysis of previously published studies. The systematic review and meta-analysis was conducted and reported in adherence to PRISMA (Preferred Reporting Items for Systematic Reviews and Meta-Analyses) [18].

\section{Search strategy and study selection}

Two investigators have independently searched the following databases (inception to October 2019): PubMed, Embase, Web of science, EBSCO, and Cochrane library databases. The electronic search strategy has been conducted using the following key words: mometasone furoate, and asthma, and paediatric or children. We have also checked the reference lists of the screened fulltext studies to identify other potentially eligible trials.

The inclusion criteria were as follows: (i) population: children patients diagnosed with asthma; (ii) intervention treatments: mometasone furoate versus placebo; (iii) the study design was RCT.

\section{Data extraction and outcome measures}

We have extracted the following information: the author, number of patients, age, female, weight, duration of asthma and detailed methods in each group etc. Data have been extracted independently by two investigators, and discrepancies were resolved by consensus. We have also contacted the corresponding author to obtain the data when necessary.

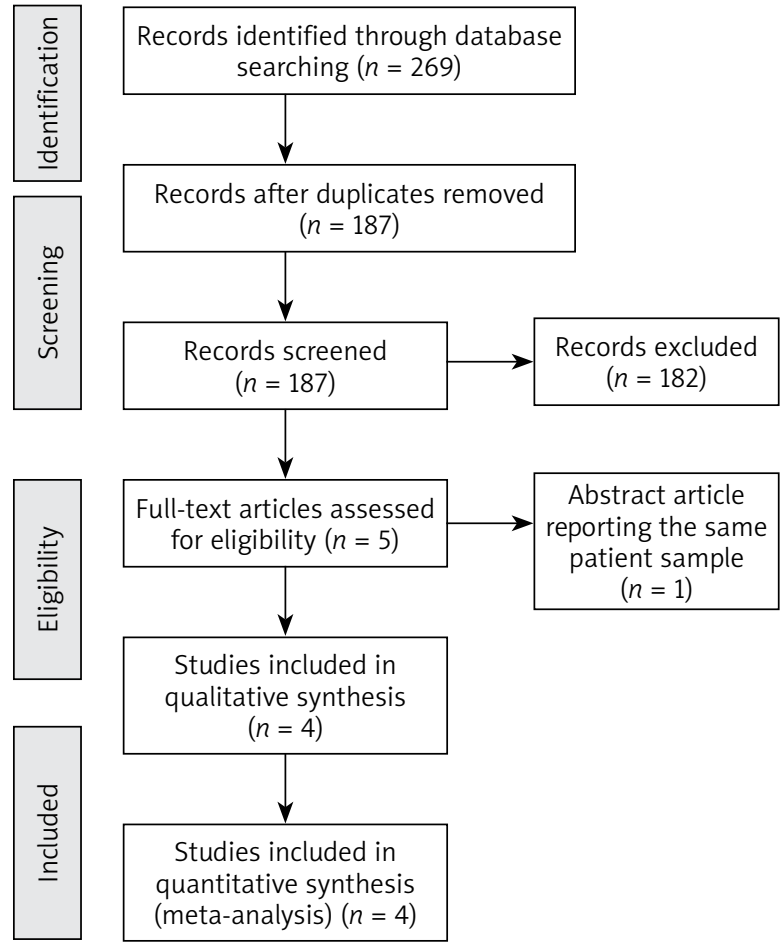

Figure 1. Flow diagram of the study search and selection process
The primary outcome was predicted forced expiratory volume in $1 \mathrm{~s}\left(F E V_{1}\right)$ and $F E V_{1}$. Secondary outcomes included morning peak expiratory flow (AM PEF), pharyngitis, upper respiratory tract infection, and adverse events.

\section{Quality assessment in individual studies}

Methodological quality of the included studies was independently evaluated using the modified Jadad scale [19]. There are 3 evaluation items for Jadad scale: randomization ( $0-2$ points), blinding ( $0-2$ points), dropouts and withdrawals (0-1 points). The score of Jadad scale varies from 0 to 5 points. An article with Jadad score $\leq 2$ is considered to be of low quality. If the Jadad score $\geq 3$, the study is thought to be of high quality [20].

\section{Statistical analysis}

We estimated the difference (MD) with 95\% confidence interval $(\mathrm{Cl})$ for continuous outcomes (predicted $\mathrm{FEV}_{1}, \mathrm{FEV}_{1}$, and $\mathrm{AM} \mathrm{PEF}$ ) and risk ratio (RR) with $95 \% \mathrm{Cl}$ for dichotomous outcomes (pharyngitis, upper respiratory tract infection, and adverse events). A random-effects model was used regardless of heterogeneity [21]. Heterogeneity was reported using the $l^{2}$ statistic, and $R^{2}>50 \%$ indicated significant heterogeneity [21, 22]. Whenever significant heterogeneity was present, we searched for potential sources of heterogeneity via omitting one study in turn for the meta-analysis or performing subgroup analysis. All statistical analyses were performed using Review Manager Version 5.3 (The Cochrane Collaboration, Software Update, Oxford, UK).

\section{Results}

\section{Literature search, study characteristics and quality} assessment

A detailed flowchart of the search and selection results is shown in Figure 1. Two hundred and sixty-nine potentially relevant articles were identified initially. Finally, four articles that meet our inclusion criteria were included in the meta-analysis [14, 23-25].

The baseline characteristics of the four eligible RCTs in the meta-analysis are summarized in Table 1. The four studies were published between 2006 and 2017, and sample sizes ranged from 89 to 225 with a total of 704 . Two studies report mometasone furoate $100 \mu \mathrm{g}$ once daily [14, 25], while the other two studies report mometasone furoate $100 \mu \mathrm{g}$ twice daily [23, 24].

Among the four studies included here, three studies report predicted $\mathrm{FEV}_{1}[14,23,25]$, two studies report $\mathrm{FEV}_{1}$ $[14,25]$, two studies report AM PEF $[23,25]$, three studies report pharyngitis and upper respiratory tract infection $[14,23,24]$, and two studies report adverse events [14, 23, 25]. Jadad scores of the four included studies vary from 3 to 5, and all four studies are considered to be highquality ones according to quality assessment. 


\section{Primary outcomes: predicted $\mathrm{FEV}_{1}$ and $\mathrm{FEV}_{1}$}

These outcome data were analysed using the random-effects model, and compared to the control group for paediatric asthma, mometasone furoate can significantly improve predicted $\mathrm{FEV}_{1}(\mathrm{MD}=7.53 ; 95 \% \mathrm{Cl}: 7.02-$ 8.04; $p<0.00001)$ with no heterogeneity among the studies $\left({ }^{2}=0 \%\right.$, heterogeneity $\left.p=0.66\right)$ (Figure 2$)$ and $\mathrm{FEV}_{1}(\mathrm{MD}=0.11 ; 95 \% \mathrm{Cl}: 0.10-0.12 ; p<0.00001)$ with no heterogeneity among the studies $(R=0 \%$, heterogeneity $p=0.70$ ) (Figure 3).

\section{Sensitivity analysis}

No heterogeneity was observed for the primary outcomes, and thus we have not performed the sensitivity analysis by omitting one study in turn to detect the heterogeneity.

\section{Secondary outcomes}

In comparison with placebo for paediatric asthma, mometasone furoate demonstrates an increase in AM PEF $(\mathrm{MD}=17.70 ; 95 \% \mathrm{Cl}$ : 9.91-25.49; $p<0.00001$; Figure 4), but has no obvious impact on pharyngitis ( $R R=0.96$; 95\% Cl: 0.59-1.58; $p=0.89$; Figure 5), upper respiratory tract infections $(\mathrm{RR}=0.73 ; 95 \% \mathrm{Cl}: 0.50-1.05 ; p=0.09$; Figure 6), or adverse events ( $R R=1.05$; $95 \% \mathrm{Cl}$ : 0.84-1.31; $p=0.69 ;$ Figure 7 ).

\section{Discussion}

Inhaled corticosteroids are widely used to decrease the symptoms and the risk of asthma exacerbations, and initiation of ICS treatment or in combination with shortacting $\beta 2$-agonists (SABA) is recommended in patients with the risk of exacerbations for inhibiting a long-term decline in lung function [26-29]. Mometasone furoate is a highly potent topical corticosteroid with negligible systemic bioavailability, and is available in a dry-powder inhaler for the treatment of asthma. Several trials found that mometasone furoate was efficacious and well tolerated in adolescent and adult patients who were receiving ICS maintenance therapy or only SABA [16, 30-32].

Our meta-analysis suggests that mometasone furoate can substantially improve predicted $\mathrm{FEV}_{1}, \mathrm{FEV}_{1}$ and AM PEF for children with asthma to a greater extent than placebo. In addition, mometasone furoate at a dose of $100 \mu \mathrm{g}$ qd resulted in a significant improvement in quality of life compared to placebo, as evidenced by the Paediatric Asthma Quality of Life Questionnaire with Standardized Activities scores, with a difference of 0.22 points ( $p=0.014$ ) [23]. Regarding the sensitivity analysis, although there is no significant heterogeneity analysis, different doses of mometasone furoate and treatment duration may have some impact on the pooling results.

In a 12-week, multicentre, double-blind, parallel-group, placebo-controlled study evaluating 2 dosing regimens

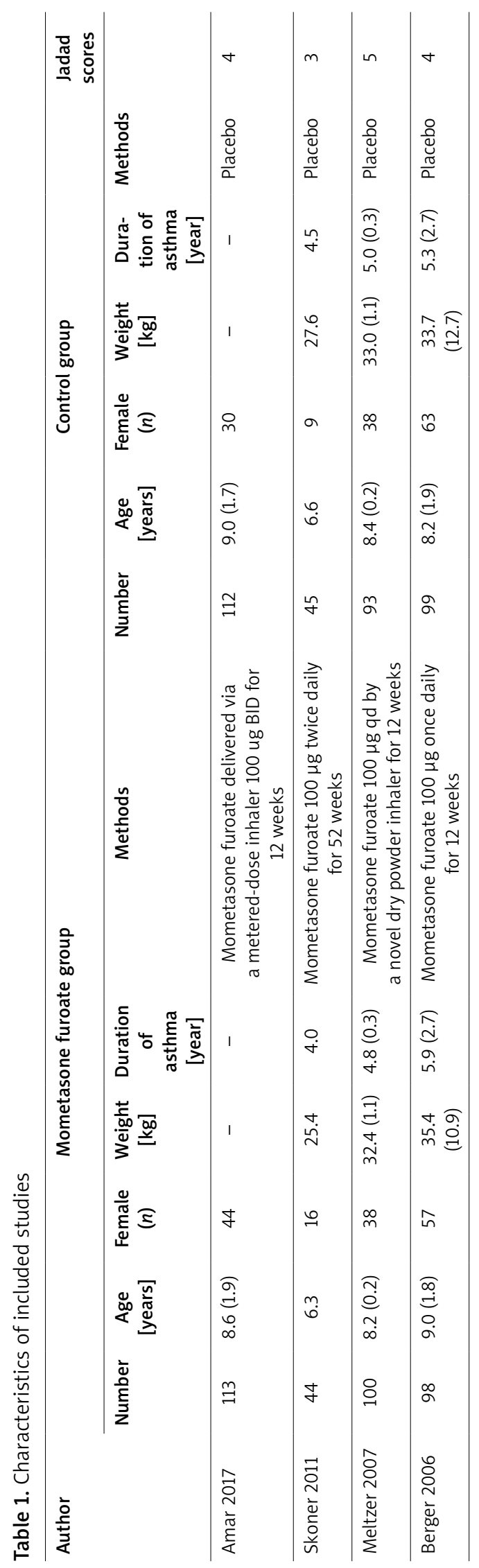




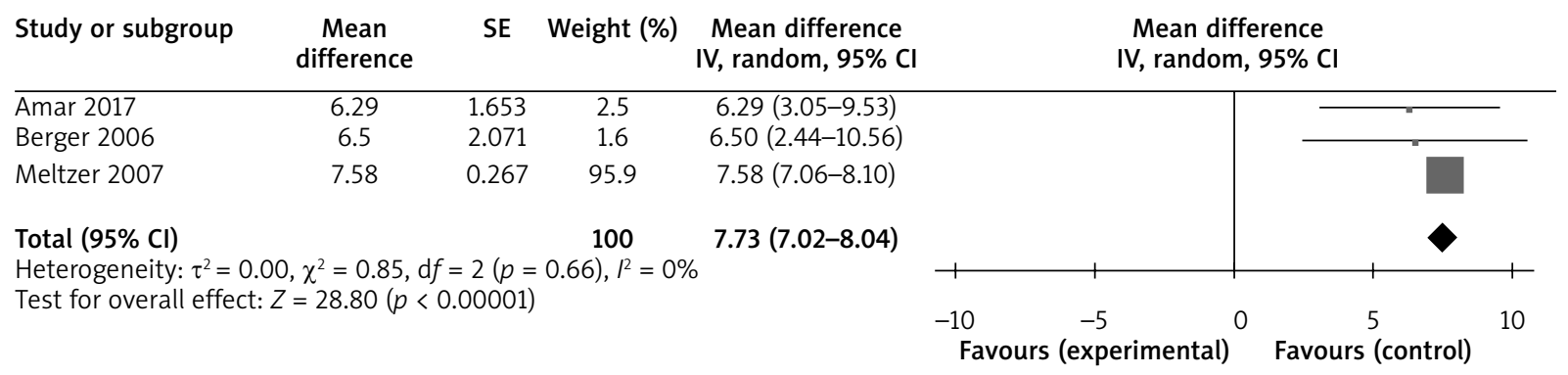

Figure 2. Forest plot for the meta-analysis of $\mathrm{FEV}_{1} \%$

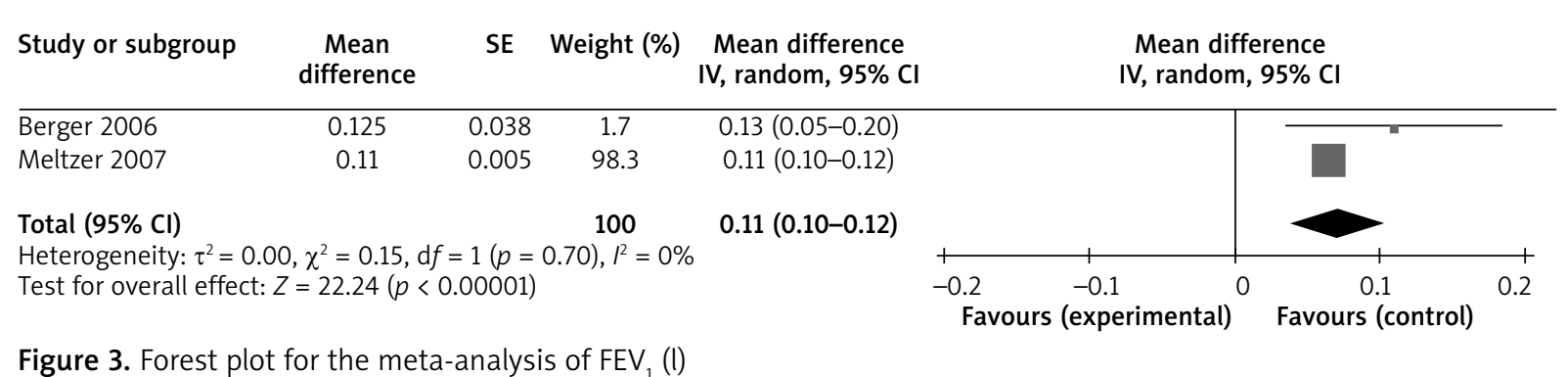

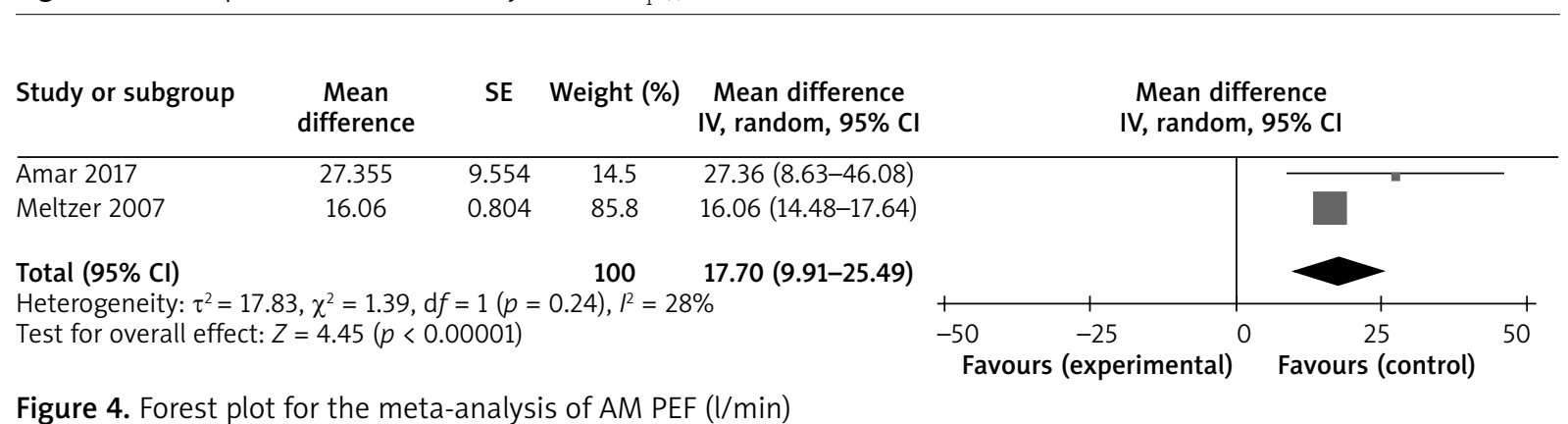

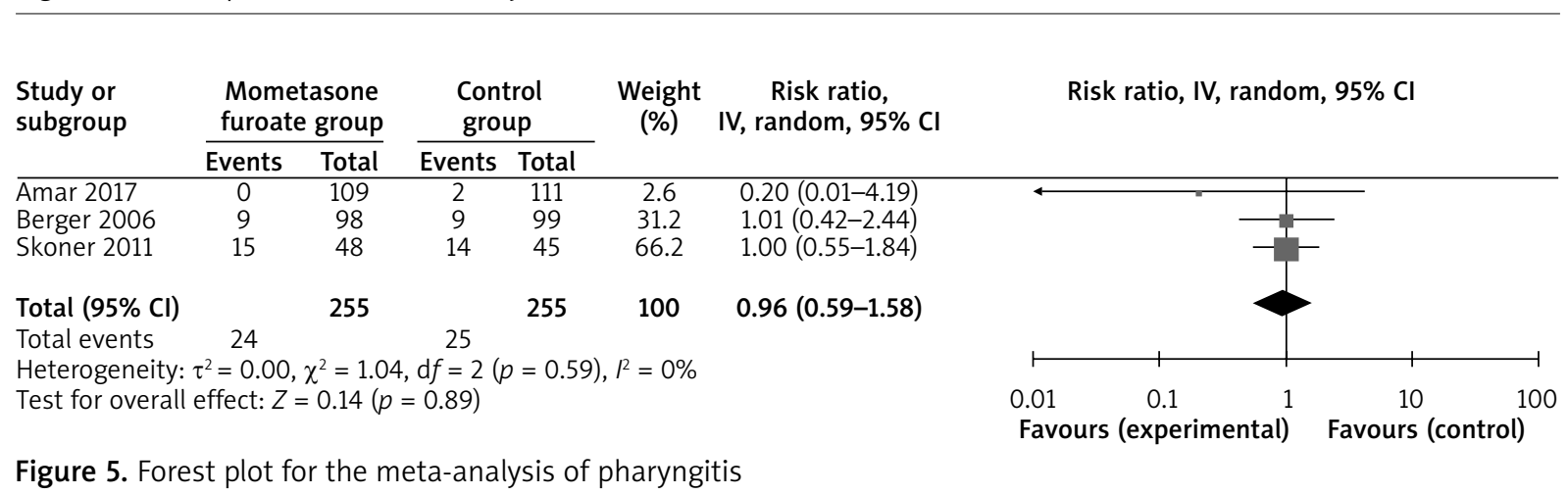

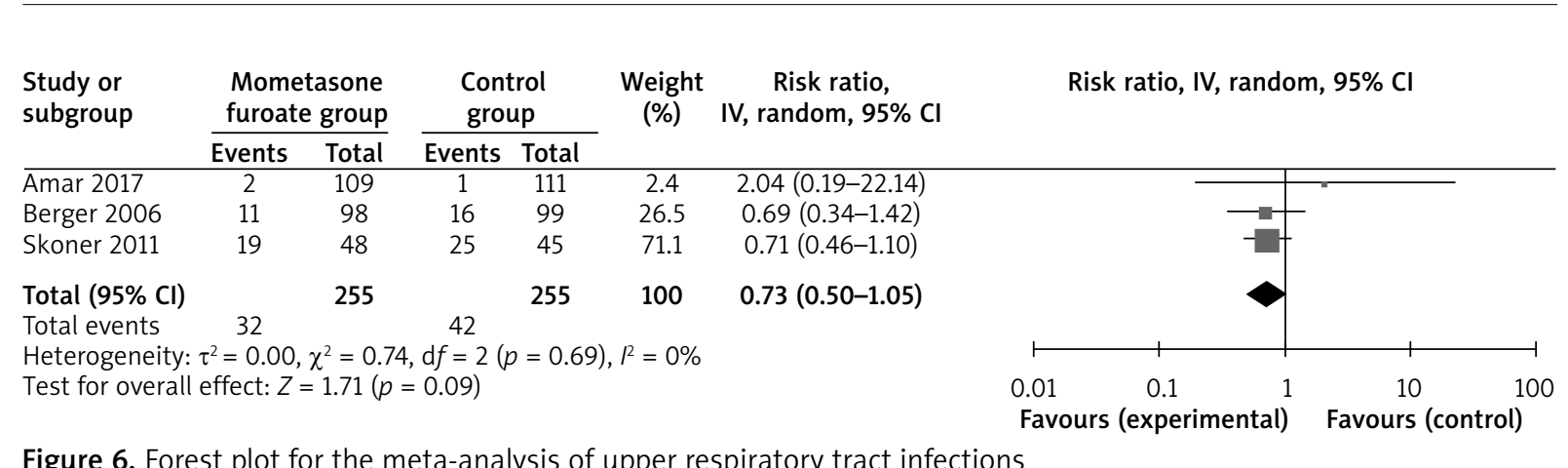

Figure 6. Forest plot for the meta-analysis of upper respiratory tract infections 


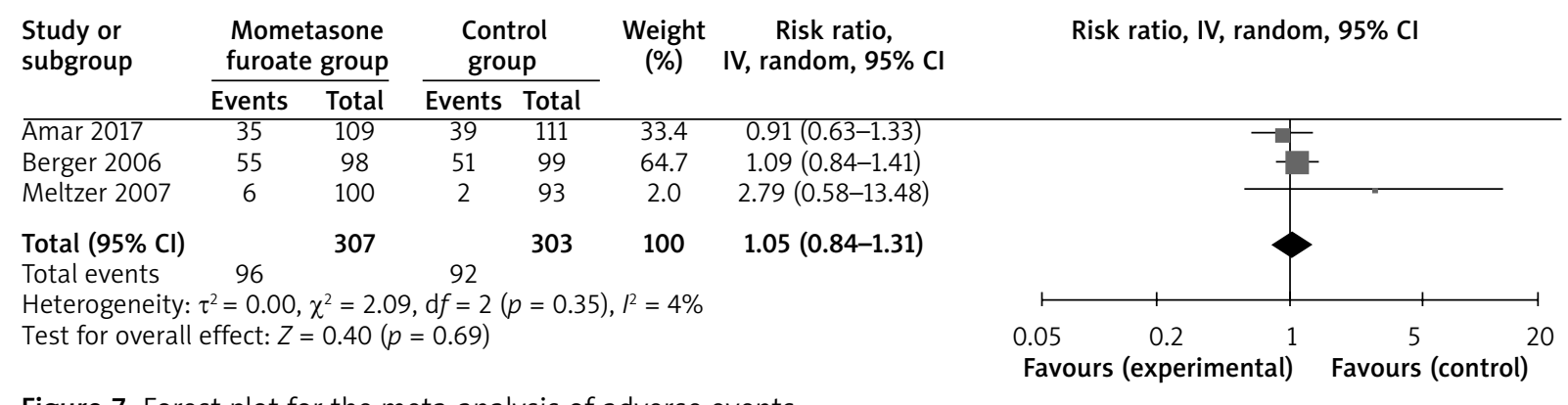

Figure 7. Forest plot for the meta-analysis of adverse events

of mometasone furoate DPI (100 $\mu \mathrm{g}$ every evening and $100 \mu \mathrm{g}$ twice daily) in 296 children aged 4 to 11 years with asthma, predicted $\mathrm{FEV}_{1}$ were 4.73 and 5.52 percentage points for mometasone furoate at a dose of $100 \mu \mathrm{g}$ daily and $100 \mu \mathrm{g}$ twice daily, respectively. Both of these two doses demonstrated an important improvement in lung function to a higher extent than placebo. However, the difference of two doses was not significant [14]. In one RCT involving children with asthma included in this meta-analysis, all three doses of mometasone furoate treatment $(50 \mu \mathrm{g}$ BID, $100 \mu \mathrm{g}$ BID, $200 \mu \mathrm{g}$ BID) demonstrated statistically significant differences of predicted $\mathrm{FEV}_{1}$ compared to placebo. Mometasone furoate at doses of $100 \mu \mathrm{g}$ BID and 200 $\mu \mathrm{g}$ BID induced the efficacy by increasing predicted FEV approximating a five percentage-point difference compared to placebo, and the $50 \mathrm{\mu g}$ BID mometasone furoate demonstrated the sub-maximal efficacy. Mometasone furoate $200 \mu \mathrm{g}$ BID showed no further improvement over the mometasone furoate $100 \mu \mathrm{g}$ BID, but was even associated with numerically slightly lower efficacy than mometasone furoate $100 \mu \mathrm{g}$ BID [23]. This revealed the effect of various doses of mometasone furoate on treatment efficacy, and $100 \mu \mathrm{g}$ BID may be the ideal dose of mometasone furoate for the treatment of paediatric asthma.

Similar incidences of pharyngitis, upper respiratory tract infections and total adverse events were observed in mometasone furoate and placebo groups based on the results of this meta-analysis. There are several potential limitations. Firstly, our analysis is based on four RCTs, and more RCTs with a large sample size should be conducted to explore this issue. Next, different doses of mometasone furoate and treatment duration may have some influence on the pooling results. Finally, some unpublished and missing data may lead to some bias for the pooled effect.

\section{Conclusions}

Mometasone furoate may provide treatment efficacy for children with asthma.

\section{Conflict of interest}

The authors declare no conflict of interest.

\section{References}

1. Wenzel SE, Jayawardena S, Graham NM, et al. Severe asthma and asthma-chronic obstructive pulmonary disease syndrome - authors' reply. Lancet 2016; 388: 2742.

2. Pavord ID, Beasley R, Agusti A, et al. After asthma: redefining airways diseases. Lancet 2018; 391: 350-400.

3. Zachary CY, Scott TA, Foggs M, Meadows JA. Asthma: an IIlustration of Health Care Disparities. Ann Allergy Asthma Immunol 2019; doi: 10.1016/j.anai.2019.11.011.

4. Ramratnam SK, Bacharier LB, Guilbert TW. Severe asthma in children. J Allergy Clin Immunol Practice 2017; 5: 889-98.

5. Bao Y, Chen Z, Liu E, et al. Risk factors in preschool children for predicting asthma during the preschool age and the early school age: a systematic review and meta-analysis. Curr Allergy Asthma Rep 2017; 17: 85.

6. Ibrahim NK, Alhainiah M, Khayat M, et al. Quality of Life of asthmatic children and their caregivers. Pak J Med Sci 2019; 35: 521-6.

7. Kansen HM, Le TM, Meijer Y, et al. Perceived triggers of asthma impair quality of life in children with asthma. Clin Exp Allergy 2019; 49: 980-9.

8. Bateman ED, Hurd S, Barnes P, et al. Global strategy for asthma management and prevention: GINA executive summary. Eur Respir J 2008; 31: 143-78.

9. Lazarus SC, Krishnan JA, King TS, et al. Mometasone or tiotropium in mild asthma with a low sputum eosinophil level. N Engl J Med 2019; 380: 2009-19.

10. Urdaneta E, Tunceli K, Gates D. Effect of mometasone furoate nasal spray on moderate-to-severe nasal congestion in seasonal allergic rhinitis: a responder analysis. Allergy Asthma Proc 2019; 40: 173-9.

11. Weinstein CLJ, Ryan N, Shekar T, et al. Serious asthma events with mometasone furoate plus formoterol compared with mometasone furoate. J Allergy Clin Immunol 2019; 143: 1395-402.

12. Meteran H, Backer V. Mometasone furoate nasal spray for the treatment of asthma. Exp Opin Investig Drugs 2016; 25: 999-1004.

13. Fausnight TB, Craig TJ. Mometasone furoate dry powder inhaler for the treatment of asthma. Exp Opin Pharmacother 2011; 12: 2707-12.

14. Berger WE, Milgrom H, Chervinsky P, et al. Effects of treatment with mometasone furoate dry powder inhaler in children with persistent asthma. Ann Allergy Asthma Immunol 2006; 97: 672-80.

15. Milgrom H. Mometasone furoate in children with mild to moderate persistent asthma. Pediatric Drugs 2010; 12: 213-21.

16. Nayak AS, Banov C, Corren J, et al. Once-daily mometasone furoate dry powder inhaler in the treatment of patients with 
persistent asthma. Ann Allergy Asthma Immunol 2000; 84: 417-24.

17. Karpel JP, Busse WW, Noonan MJ, et al. Effects of mometasone furoate given once daily in the evening on lung function and symptom control in persistent asthma. Ann Pharmacother 2005; 39: 1977-83.

18. Moher D, Liberati A, Tetzlaff J, et al. Preferred reporting items for systematic reviews and meta-analyses: the PRISMA statement. J Clin Epidemiol 2009; 62: 1006-12.

19. Jadad AR, Moore RA, Carroll D, et al. Assessing the quality of reports of randomized clinical trials: is blinding necessary? Control Clin Trials 1996; 17: 1-12.

20. Kjaergard LL, Villumsen J, Gluud C. Reported methodologic quality and discrepancies between large and small randomized trials in meta-analyses. Ann Intern Med 2001; 135: 982-9.

21. Zhao J, Huang W, Zhang S, et al. Efficacy of glutathione for patients with cystic fibrosis: a meta-analysis of randomizedcontrolled studies. Am J Rhinol Allergy 2020; 34: 115-21.

22. Higgins JP, Thompson SG. Quantifying heterogeneity in a meta-analysis. Stat Med 2002; 21: 1539-58.

23. Amar NJ, Shekar T, Varnell TA, et al. Mometasone furoate (MF) improves lung function in pediatric asthma: a double blind, randomized controlled dose ranging trial of MF metered dose inhaler. Pediatr Pulmonol 2017; 52: 310-8.

24. Skoner DP, Meltzer EO, Milgrom H, et al. Effects of inhaled mometasone furoate on growth velocity and adrenal function: a placebo-controlled trial in children 4-9 years old with mild persistent asthma. J Asthma 2011; 48: 848-59.

25. Meltzer EO, Baena-Cagnani CE, Chervinsky P, et al. Once-daily mometasone furoate administered by dry powder inhaler for the treatment of children with persistent asthma. Pediatr Asthma Allergy Immunol 2007; 20: 67-82.

26. (GINA) GIfA. Global strategy for asthma management and prevention. Available from: wwwginasthmaorg Accessed 25 March 2015. 2015

27. Eltonsy S, Forget A, Beauchesne MF, Blais L. Risk of congenital malformations for asthmatic pregnant women using a long-acting beta2-agonist and inhaled corticosteroid combination versus higher-dose inhaled corticosteroid monotherapy. J Allergy Clin Immunol 2015; 135: 123-30. e2.

28. Reddel HK, Busse WW, Pedersen S, et al. Should recommendations about starting inhaled corticosteroid treatment for mild asthma be based on symptom frequency: a post-hoc efficacy analysis of the START study. Lancet 2017; 389: 15766.

29. Kew KM, Dahri K. Long-acting muscarinic antagonists (LAMA) added to combination long-acting beta 2-agonists and inhaled corticosteroids (LABA/ICS) versus LABA/ICS for adults with asthma. Cochrane Database Syst Rev 2016; 1: CD011721.

30. Noonan M, Karpel J, Bensch G, et al. Comparison of oncedaily to twice-daily treatment with mometasone furoate dry powder inhaler. Ann Allergy Asthma Immunol 2001; 86: 36-43.

31. D'Urzo A, Karpel JP, Busse WW, et al. Efficacy and safety of mometasone furoate administered once-daily in the evening in patients with persistent asthma dependent on inhaled corticosteroids. Curr Med Res Opin 2005; 21: 1281-9.

32. Bernstein D, Berkowitz R, Chervinsky P, et al. Dose-ranging study of a new steroid for asthma: mometasone furoate dry powder inhaler. Respir Med 1999; 93: 603-12. 